\title{
Resumiendo documentos audiovisuales televisivos: propuesta metodológica
}

Jorge Caldera-Serrano

\begin{abstract}
Profesor del área de Biblioteconomía y Documentación, del Departamento de Información y Comunicación de la Universidad de Exrtremadura.Docencia en la Facultad de Ciencias de la Documentación y la Comunicación Espanha
\end{abstract}

http://dx.doi.org/10.1590/1981-5344/1866

Se realiza una propuesta metodológica para la confección del resumen de documentos audiovisuales televisivos, identificando y describiendo las etapas necesarias para su redacción. Previo a esta labor se analizan sobre qué documentos audiovisuales debe realizarse dicha operación así el cómo ha modificado el paradigma digital el tratamiento documental. Se constata la necesidad de realizar el resumen documental en ciertos tipos documentales, siendo innecesario para otros derivado de su escasa duración.

Palabras claves: Resumen documental; Documentación audiovisual; Medios de comunicación audiovisual; Tratamiento documental; Paradigma digital.

\section{Abstract audiovisual television: a methodological proposal}

It made a proposal to the preparation of the abstract of the audiovisual information, identifying and describing the steps needed for writing. Prior to this work we analyze audiovisual what should be done and how the operation has changed the digital paradigm documentary treatment. It notes the need for the documentary short documentaries certain types, being unnecessary for other derivative of its short duration.

Keywords: Abstract documentary; Audio-visual documentation; Mass media; Documentary treatment; Digital paradigm. 


\section{La industria de la comunicación y los departamentos de documentación}

Los cambios que se están produciendo en los medios de comunicación son trepidantes. Los procesos de digitalización que se comenzaron a llevar a cabo especialmente en la década pasada, y que en la actualidad aún se siguen desarrollando en muchas de las cadena, se ha ralentizado en cierta manera por un nuevo cataclismo entre los medios de comunicación. La crisis económica que asola especialmente a los países mediterráneos unido a la vertiginosa implantación y desarrollo de las redes sociales entre los nuevos consumidores de los medios, hacen necesario una adaptación de los medios a nuevas formas y formatos, y a un modelo de negocio donde no sólo se debe aportar información, ya que dicha información está al alcance de prácticamente toda la población que está conectada a la red, sino que también se debe aportar calidad, reflexión, investigación y valoración.

Actualmente estos cambios se están traduciendo en reajustes de personal, sino en cierre de medios de comunicación, cambio a un tipo de periodismo más incisivo y de investigación, y muy especialmente en la adaptación de los medios a las tecnologías y aplicaciones para la red.

Los nativos digitales se han formado y se han desarrollado entre pantallas, las del ordenador, la de la consola, de la televisión y por supuesto, la del teléfono. Estos requieren nuevas formas de entender el periodismo sino se quiere seguir el camino hacia un desapego importante ante los medios. Estos nativos digitales prefieren ahora la información facilitada por iguales por medio de blogs, redes sociales o microbloging, que la aportada por los medios de comunicación.

Y es en este punto, donde los departamentos de documentación de las empresas de comunicación cobran una especial relevancia: los servicios de documentación aportan calidad, reflexión, ayudan a la investigación y a la valoración de la información vertida por los medios tanto en las plataformas tradicionales como en los actuales formatos digitales.

Contar con un departamento de documentación no es ya un lujo sino una necesidad de todos los medios. $Y$ aunque en nuestro caso, nos centremos en los televisivos, los requerimientos son idénticos para los diferentes medios, cambiando por supuesto, los formatos y las maneras de conservación y descripción.

La función verificadora y completiva son necesarias para ofrecer información de actualidad de calidad, además de ser cada vez más un factor clave para el desarrollo de investigaciones por parte del personal de la cadena. Ahora, más que nunca, la información es poder.

\section{El tratamiento documental en las televisiones}


Tras la revisión de diferentes autores, las etapas o elementos que se realizan en la descripción documental del material audiovisual - de manera general - son el de visionado, resumen e indización. De todo el material audiovisual que se acumula en los centros de documentación televisivos, el análisis documental se realiza sobre toda la producción seleccionada para ser conservado. Por lo tanto, el tratamiento se efectuará sobre documentos susceptibles de explotación documental.

Son varios los tratados que han intentado esquematizar dicho proceso de análisis desde un punto de vista teórico aunque, por otro lado, son escasos los que se sumergen en la práctica diaria. A pesar de que varios autores han tratado de crear una metodología para el análisis de las imágenes, la mayor parte de ellos se nutren del trabajo presentado por Catherine Fournial (1986) bajo el título "Análisis documental de imágenes en movimiento" en Panorama de los Archivos Audiovisuales publicado en 1986; conviene, de este modo, destacar su importancia y actualidad.

Visionado. Antes de entrar en el análisis de cualquier pieza audiovisual, el documento tiene que visualizarse en su totalidad. No hay que detenerse solamente en la banda imagen sino que será igualmente necesario atender a la banda sonora. Como apoyo a esta función, es recomendable que el documentalista cuente con partes de grabación, planes de rodaje, resúmenes de puesta en escena, planes de montaje, etc.

Las notas a tomar durante el primer visionado deben indicar la pertinencia del documento así como el nivel de análisis, lo cual puede depender de factores tales como el tipo de programa y el potencial de reutilización. Se deben metodizar los diferentes planos con los que se ha montado la pieza, destacando tanto a los personajes, lugares y temas visionados en el documento. Si fuera necesario, se realizará la descripción secuencia a secuencia de las imágenes, cuando ésta cobre especial relevancia.

Esta labor es un tanto complicada y delicada; supone mucho tiempo de trabajo, lo cual será al menos cinco veces el tiempo que se necesita para un visionado continuo del documento.

La descripción de planos se denomina "análisis cronológico" o "minutado" y consiste en anotar - conforme se van sucediendo los acontecimientos -, los planos y secuencias que configuran el contenido y la forma del documento, reseñando tanto a personajes, lugares, temas como todas aquellas cuestiones que se consideren relevantes desde el punto de vista visual o sonoro.

El tipo de análisis será diferente en función del tipo de programa. El potencial de uso de unas imágenes pertenecientes a un Informativo difiere de las correspondientes a un programa de entretenimiento. Durante el análisis se persigue la precisión, buscando los conceptos sin ningún tipo de ambigüedad; se intenta que la descripción sea objetiva, aunque las referencias culturales del documentalistas conllevan un alto grado de subjetividad en la descripción del documento. 
Resumen. Mientras que por medio del análisis cronológico se describen las diferentes secuencias o planos, mediante el resumen se analiza el documento en su conjunto. Repetimos que el usuario solicita tanto material audiovisual general como planos específicos.

El resumen tiene que ser sintético, como sustituto de todo el documento. Se realiza tras la visualización y normalmente, una vez se ha redactado el análisis cronológico. Debe señalar los principales temas y destacar aquellas informaciones e imágenes de interés para su posterior uso. El tipo de resumen se efectúa de acuerdo con el programa y la procedencia de las imágenes.

La indización de la información contenida en el documento audiovisual ha de llevarse a cabo por medio de un lenguaje controlado; no todos los archivos utilizan únicamente esta fórmula de descripción, y junto al lenguaje documental utilizan palabras claves en lenguaje libre.

Esta herramienta de trabajo debe incluir tanto personas físicas como jurídicas, lugares geográficos así como términos abstractos que sirvan para la descripción temática del documento. Igualmente es necesario que, por medio de estos términos, se consignen datos de localización así como datas cronológicas.

Como se ha apuntado al principio, otros trabajos publicados con posterioridad toman como punto de partida las ideas aportadas por Fournial (1986).

Así, el Manual de documentació Audiovisual e ràdio i televisió (1999) presenta cuáles son las etapas que engloban el análisis documental audiovisual desde una perspectiva teórica y práctica: Elementos de identificación (visionado): lectura banda imagen y lectura banda sonido; resumen; e indización.

Esta metodología en poco se aleja de la ofrecida por Fournial (Incluye una primera fase en la cual se identifican los aspectos formales del soporte y de las imágenes antes del visionado. Esta misma idea la recoge también Eugenio López de Quintana bajo el título Documentación audiovisual: metodología para el análisis documental de la información periodística audiovisual (QUINTANA, 1992), y en concreto el capítulo V "El análisis documental de documentos periodísticos audiovisuales: propuesta de un método de análisis". En él desarrolla y analiza las siguientes fases: lectura y percepción del documento periodístico audiovisual; síntesis de documentos periodísticos (resumen); y representación por medio de descriptores.

Un trabajo relevante sobre el análisis documental es el que realiza López de Quintana con un capítulo dedicado a la Documentación en Televisión en Manual de Documentación Informativa (QUINTANA, 2000). Aunque se apoya en las mismas fases presentadas en el manual valenciano mencionado previamente, explica de forma más detallada cada una de esas fases de análisis y apunta los datos que debe aportar cada una: identificación básica sin visionado (código de cinta -en material analógico-, formato, tipo de grabación, título); visionado (determinación del nivel de análisis, descripción de plano, indización y/o resumen). Modifica la forma de las distintas fases aunque el resultado y las 
operaciones sean las mismas. Incluye todas las operaciones de análisis de contenido en una única fase compuesta por subfases, pero las tareas son idénticas.

También hay que mencionar el capítulo de Hidalgo Goyanes Análisis documental de audiovisuales"; incluido en el manual Introducción a la documentación informativa y periodística (GOYANES, 1999). Las fases señaladas son un resumen temático o conceptual del contenido total del documento; descripción detallada de la información visual y sonora relevante; y palabras claves o descriptores.

El resumen está presente en todas las fases indicada por los autores, no obstante es sin lugar a dudas la menos descrita y sistematizada.

\section{En resumen, resumimos}

\subsection{Qué es un resumen}

Existe sobre esta materia literatura abundante y especialistas muy destacados. Utilizamos la definición aportada por Moreiro (2004) que lo define como operación por medio de la cual se explica de manera abreviada y precisa la información sustancial de un documento, utilizando para ello el lenguaje natural como transmisor. Señala igualmente que dicho resumen debe estar acorde con la normalidad de expresión de la lengua utilizada, respetando los posibles límites impuesto por normativas al documentalista y los límites impuestos por la actuación informativa.

Por lo tanto es un texto que reproduce otro documento (no siempre otro texto), por lo que mucha información no está presente en dicho resumen. En el resumen debe estar lo verdaderamente importante y central del documento original.

El mismo autor señala los fines del resumen, a saber:

a)reproducir el contenido del original de forma breve;

ayuda a determinar la relevancia del original para los requerimientos del usuario;

b)facilita la comprensión del original, cuando su lectura es previa al documento completo;

c)puede sustituir al original, por limitaciones del usuario en el idioma o en la posibilidad de acceso;

d)puede ser empleado como elemento de recuperación de la información;

e)como método de transcodificación, para mensajes expresados a través de imágenes y sonidos, para los cuales es necesario su transcripción a texto para poder ser recuperados. 
Todos los fines señalados son válidos para los documentos audiovisuales tal y como veremos posteriormente.

\subsection{Qué documentos deben resumirse y cuáles no}

No existe en la literatura científica que versa sobre la documentación audiovisual en televisión un estudio claro sobre cómo hacer un resumen para este tipo de documentos, ni tampoco cuáles son susceptibles de sufrir este tratamiento documental. La praxis profesional nos demuestra que se realizan en muy diversos momentos y sobre diversos tipos documentales, siendo en muchos casos de diferente profundidad, longitud y complejidad. Como en casi todo en el ámbito de lo audiovisual no existe acuerdo ni entre cadenas ni entre entidades de carácter supranacional que trabajen sobre esta materia (véase FIAT/IFTA, IASA, AMIA, etc. ).

A priori todos los tipos documentales pudieran realizarse un resumen documental, ahora bien, habrá que plantearse su utilidad atendiendo a cuestiones tales como la extensión del documento original, formato audiovisual así cómo los requerimientos documentales de los periodistas de las empresas audiovisuales televisivas.

En lo que se refiere a productos presentes en los Servicios Informativos nos encontramos material montado y de escasa duración (emisiones), material sin montar y de duración variable (brutos), y material semimontado y con duración raramente superior a los seis minutos (brutos, material de centros territoriales, corresponsalías, enviados especiales y material de agencia). Existen otros tipos documentales (máster, copia de seguridad, paralelo de antena, etc.) pero que pueden ser incluidas dentro de los tipos propuestos.

Las emisiones son de escasa duración, y hemos de tener presente que el tratamiento documental de este material cuenta además con un título documental, que debe aportar al menos el quién y el qué de la noticia, y una descripción de las imágenes de forma más o menos detallada. Por lo tanto, no parece oportuno el realizar un resumen cuando con un rápido vistazo de la descripción de imágenes podemos conocer el contenido del documento.

Existe discrepancias y divergencias sobre si realizar resúmenes sobre el material semimontado. El por qué viene determinado por los factores señalados con anterioridad: cuenta con un título documental redactado en lenguaje libre donde se destaca los elementos más relevantes de la información, y además cuenta con la descripción de imágenes (también denominado análisis cronológico o minutado) (CALDERA; JIMENEZ, 2008)

Aunque somos conocedores de que algunas cadenas de televisión realizan estos resúmenes, estimamos que no son realmente necesario por los argumentos ya expresados. Además, aquellas cadenas que realizan esta operación documental no suelen realizarlo con más de dos o tres líneas (unas cincuenta palabras) por lo que intentan completar la información por medio de la descripción de imágenes, aunque dicha 
información ya es aportada por los descriptores temáticos, onomásticos y geográficos, además de aportarlo el título documental.

Sin embargo, sí que parece relevante realizar el resumen sobre los brutos. Los brutos son el material captado directamente por el reportero, por lo que hablamos de un documento primario, sin montar y sin locutar, material que puede contar con movimientos irregulares de cámara y repetición de tomas, donde podremos encontrar tanto totales (declaraciones) como recursos (imágenes donde la locución carece de importancia).

En el tratamiento documental dichos brutos, a veces, van unidos a otros tipos documentales como podrían ser la emisión. No obstante, los brutos no cuentan con material anexo que los describa ni que ayude a su entendimiento, salvo en algunas ocasiones que cuentan con los partes de grabación realizados por los cámaras en los cuales se identifica algunas personas y momentos de la grabación. Además, este material no cuenta con una descripción muy detallada en la descripción de imágenes ya que, al ser material de larga duración en algunos casos, se realiza una selección del material analizado, destacando sólo aquellos que el documentalista estima relevante.

Por lo tanto, el resumen realizado por el personal de la cadena debe completar a la descripción de imágenes que no describe en su totalidad el documento.

Aunque dicho material bruto vaya acompañando a otros tipos, como las emisiones o paralelos de antena, sí que se estima pertinente la realización del resumen, ya que la emisión no deja de ser un mero extracto, a veces interesado, del total de imágenes captadas por la cámara de la cadena.

\subsection{Programas de entretenimiento}

Para otro tipo de programas, como talk show, reality show, magazine, etc., sí que parece pertinente la realización de un resumen, derivado de que su tratamiento documental nunca será tan exhaustivo como el del material de informativos. Los motivos es que la valía para su explotación posterior no es tan relevante al haber mucho material en estudio con escasa relevancia futura.

Algunos de estos programas son bastante complejos, donde se suele mezclar información de actualidad con espectáculo, por lo que se podría a llegar a tratar de forma separada aquellas partes que versan sobre información de actualidad o de sociedad.

Aquí los resúmenes, por lo tanto, son fundamentales para conocer el alcance y contenido del programa, resúmenes que se convierten en una pieza clave en la recuperación documental del material.

\section{Cambio con el paradigma digital}

Los métodos de análisis documental se han modificado con la llegada de la digitalización a las redacciones y, por lo tanto, a los servicios 
de documentación. Las cadenas cuentan con sistemas rápidos y dinámicos de acceso a la información, donde la inmediatez y el acceso simultáneo a contenidos a mutado la relación entre la redacción y el servicio de documentación.

Cada vez más, las intranet corporativa se ha convertido en el auténtico puente e intermediario para el acceso a la información, y por lo tanto, el rol del documentalista está cambiando.

Otra mutación se está desarrollando en el análisis documental. Actualmente se sigue trabajando, en muchos casos, con mentalidad analógica en entornos digitales pero existe un cambio que lo modifica todo: ahora no sólo contamos con la información referencial de la información, si no que contamos directamente con el documento original accesible de forma rápida.

A la vez que se recupera un conjunto de keyframes, noticia o programa tendremos la posibilidad de visualizar en baja resolución el resultado a la consulta. Por lo tanto, no parece oportuno la realización de una descripción tan exhaustiva si contamos con el original que cada vez se facilita más fragmentado.

Además, estas herramientas y de forma automática facilitan resúmenes visuales por medio de keyframes representativos de las imágenes recuperadas.

Podríamos hacernos la siguiente pregunta, ¿es por tanto necesario seguir describiendo imágenes, realizar resúmenes e indicar título documental? La respuesta es clara, sí. Para poder acceder a la información el método más relevante para el acceso a la información sigue siendo el acceso por información textual -metadatos- que se han ido asociando a las imágenes. No obstante actualmente ya existen otros métodos de consulta fuera del entorno textual, como la búsqueda por parámetros biométricos (CALDERA; ZAPICO, 2009), por colores y formas, etc.

\section{Fases y metodología para la confección del resumen}

El método para la realización del resumen en televisión no difiera en gran manera del que se realiza en cualquier tipo de unidad de información. Ahora bien, la naturaleza audiovisual del material hace necesario una doble traducción: de lo audiovisual a lo conceptual textual, y de éste al resumen textual. La labor de transcribir a texto lógico y coherente del material audiovisual es un ejercicio que sólo se consigue por medio de la praxis profesional, ya que nuestra tradición siempre se ha centrado en el texto como forma de transcripción de conocimiento, siendo muy recientemente cuando el material audiovisual ha cobrado relevancia en ámbitos académicos, informativos, educativos, etc.

\subsection{Primera fase: visionado del original}

Parece evidente que el visionado del documento original es obligado para la confección de un resumen, pero este visionado plantea una serie de variables que lo dificultan. Hemos de tener presente que muchos de los 
documentos audiovisuales con los que trabajan las televisiones pueden llegar a contar con horas de duración, por lo que un visionado continuo no siempre es posible. Por ello, antes del visionado, el documentalista intentará recabar cuanta información textual sea posible para posicionarse frente al documento original. Para ello es interesante conocer las escaletas, guiones de montaje, partes de grabación, etc.

Se podría estimar que la realización de un resumen de material audiovisual puede ser más sencillo al ser códigos más fácilmente asumibles, y esto es realmente así: los códigos son más asumibles para todos pero mucho más complicado su transcripción. Hemos de tener presente que el documentalista para la realización del resumen sólo cuenta con sus conocimientos y referencias culturales y sociales, no contando con herramientas de carácter audiovisual que le ayude a la comprensión.

Además existe problemas derivados de la identificación de los códigos aparecidos en las imágenes, y sobre todo, el determinar un valor futuro a aquellas partes que posteriormente serán descritas en el resumen. Reconocer personas y lugares no siempre es un ejercicio sencillo, a veces requiere de una investigación documental para su identificación.

\subsection{Extracción de información relevante}

No deja de ser complicado con la documentación audiovisual el determinar cuáles de todos los elementos representados en el documento es el más importante. La versatilidad y transversalidad de muchos documentos audiovisuales dificultan la determinación de lo sustancial y de lo superfluo.

Estimamos que un método significativo para realizar el resumen sería la contestación a las principales cuestiones planteadas por el Paradigma de Lasswell, método por el cual tradicionalmente los periodistas confeccionan su información.

Aunque mucho más evidente en medio impresos, el Paradigma de Lasswell debe dar contestación al qué ocurre en la información, quién lo ejecuta 0 es el objeto paciente, cómo ocurren esos acontecimientos, cuándo se llevan a cabo, dónde transcurre la información, y si fuera posible, el por qué. El último aspecto no siempre se observa en la información periodística que en muchos casos es meramente informativa y no reflexiva. Existen reportajes y productos audiovisuales que sí pueden llegar a resolver esta cuestión.

Pues bien, partiendo de que el periodista debe intentar responder a estar cuestiones en cualquier información audiovisual, el resumen debe plasmar estos elementos principales en su transcripción.

Volvemos a señalar que no es un ejercicio sencillo el extraer los códigos audiovisuales para llevar a cabo la contestación a estas cuestiones -las cuales algunas no serán respondidas en ocasiones por falta de 
información o por incapacidad de identificar objetos, personajes $\mathrm{y} / \mathrm{o}$ lugares-, no obstante es una buena guía para la confección de resumen de documentos audiovisuales televisivos que son, por extensión, periodísticos.

\subsection{Redacción del resumen en forma texto periodístico}

La redacción de resúmenes deberá realizarse atendido a las pautas y normativas lingüísticas del idioma en el que se confecciona. Incluso podemos tener presentes las pautas de las normas propias y conocidas para la confección de resúmenes (Normas ISO).

Ahora bien, los resúmenes de documentos audiovisuales televisivos deberían adoptar un aspecto formal acorde a los requerimientos periodísticos y al tipo de usuario: el periodista.

El resumen debe elaborarse en forma de pirámide invertida. Los elementos más relevantes deben ir ubicados al principio, de tal manera que no sea necesario la lectura de todo el resumen para su comprensión. Por lo tanto, se incluirán las ideas más destacadas para ir posteriormente bajando en la escala de importancia para identificar elementos secundarios.

Además, hemos de ser capaces de adaptarnos a la terminología y hábitos periodísticos. Esto implica el denominar a personas y lugares por la fórmula más habitual en los medios de comunicación, independientemente que sea más o menos correcto desde el punto de vista normativo.

No obstante, el resumen no debe contar con titulares "de prensa" si no con una redacción que identifique lo sustancial del documento original.

Aunque un resumen por su naturaleza y objetivo debe centrarse en el contenido general del documento, y elaborando el resumen para un medio audiovisual, podría llegar a ser relevante -si el documento así lo estimara- la identificación y marcación en el resumen de imágenes relevantes o muy importantes, haciendo para ello una rápida identificación y un enlace al clic de vídeo donde poder encontrarlo. Por lo tanto enlazamos el resumen, tradicionalmente genérico, con partes concretas especialmente útiles, válidas y/o relevantes.

Esta fórmula va a ser útil especialmente para aquellas cadenas de televisión con escasez de recursos humanos, donde la labor documental es cada vez más complicada de elaborar, utilizando por tanto el resumen no sólo como método referencial de acceso al documento, sino como enlace a imágenes que pudiera ser válidas para el usuario.

\section{Conclusiones}

Con la llegada de las redacciones digitales se ha producido un cambio importante en la gestión de la información audiovisual televisiva, no obstante esta adaptación no ha eliminado la importancia ni la valía de la labor de los gestores de información. 
El resumen es un ejemplo de herramienta de análisis de contenido que sigue teniendo vigencia para ciertos tipos de documentos. El resumen se traduce en un esfuerzo útil únicamente para documentos donde la descripción de imágenes es escasa y la extensión (en duración) es importante. De esta manera, el periodista podrá conocer aproximadamente qué contenido puede esperar al visionar el documento original.

Esta descripción puede servir de herramienta principal para aquellas cadenas con recursos humanos muy escasos y por lo tanto con la incapacidad de realizar una descripción de imágenes no sólo exhaustiva sino tan siquiera liviana. Desde el resumen se podrían enlazar aquellas imágenes significativas y relevantes, convirtiéndose por tanto en el nexo y enlace entre el usuario y el material audiovisual.

Desde aquí defendemos que antes de determinar las herramientas documentales a aplicar en el análisis de contenido debe hacerse un estudio pormenorizado de personal, requerimientos, tiempos de respuesta, tipología de usuarios y evidentemente de la producción audiovisual, para así poder determinar cuáles son las mejores para cada tipo de entidad.

La recuperación por texto libre es cada vez más generalizada desde el momento en que es el periodista quién accede directamente a la información, por lo que todos los mecanismos que ayuden a direccionar correctamente estas consultas serán bienvenidas.

\section{Reconocimientos}

Este trabajo ha sido financiado por la Junta de Extremadura (Consejería de Educación Ciencia y Tecnología) y el Fondo Social Europeo dentro del plan de apoyo a las actuaciones de los Grupos de Investigación inscritos en el catálogo de la Junta de Extremadura. GR10019.

\section{Bibliografía}

CALDERA-SERRANO, J.; ZAPICO-ALONSO, F. Biometric facial identificacion. Profesional de la Información, v. 18, n. 4, p. 427-431, 2009.

CALDERA-SERRANO， J.; SÁNCHEZ-JIMÉNEZ, R. Development and application of an ontology for onomastic information control and retrieval in television. Profesional de la Información, v. 17, n. 1, p. 86-91, 2008.

FOURNIAL, C. Análisis documental de imágenes en movimiento. En: FEDERACIÓN INTERNACIONAL DE ARCHIVOS DE TELEVISIÓN. Panorama de los archivos audiovisuales. Madrid: Servicio de Publicaciones del Ente Público RTVE, 1986. p. 249-258.

HIDALGO GOYANES, P. Análisis documental de audiovisuales. En: GARCÍA GUTIERREZ, A. Introducción a la documentación informativa $y$ periodística. Sevilla: MAD, 1999, p. 333-350. 
LÓPEZ DE QUINTANA, E. Documentación en televisión. En: MOREIRO, J. A. Manual de documentación informativa. Madrid: Cátedra, 2000. p. 83181.

MANUAL de documentació Audiovisual e ràdio i televisió (1999). València: Universitat, 1999.

MOREIRO GONZÁLEZ, J. A. El contenido de los documentos textuales: su análisis y representación mediante el lenguaje natural. Gijón: Trea, 2004. 